\title{
An evaluation of an education abroad program on the intercultural learning and cross-cultural adaptability skills of university undergraduates
}

\author{
Jennifer Fong \\ Department of Educational Policy and Leadership, University at Albany, \\ New York, USA
}

Evaluation of an education abroad program

Received 30 January 2020 Revised 10 May 2020 Accepted 1 June 2020

\begin{abstract}
Purpose - The purpose of this case study is to explore to what extent US university undergraduates participating in a research abroad program through US-Taiwan Partnerships for International Research and Education (PIRE) developed intercultural awareness and cross-cultural adaptability skills. It also suggests additional program design features to enhance students' international experiences.

Design/methodology/approach - To better understand participants' experiences in the PIRE program, this study adopts a mixed-methods approach. Demographic questionnaires, pre- and postsurveys, observational field notes and individual interviews were conducted for data collection and analysis.

Findings - Students perceived the experience abroad to improve their intercultural awareness and skills such as openness to cultural differences, coping with challenges abroad and effectively working in diverse teams. Specifically, quantitative findings reflected group gains in the areas of flexibility/openness and perceptual acuity, whereas qualitative findings indicated growth in students' emotional resilience and personal autonomy. Research limitations/implications - Additional data collection methods, such as pre-/postinstruments or a longitudinal study would provide a more comprehensive assessment of the impact of education abroad on students' intercultural learning.

Social implications - Evaluation of programs and outcomes can help identify areas to maximize student learning and assess the value of education abroad.

Originality/value - This is original research and makes a contribution to education abroad programs in postsecondary education.
\end{abstract}

Keywords Cross-cultural adaptability, Education abroad, Intercultural learning

Paper type Case study

\section{Introduction}

As the world becomes increasingly diverse, the ability to understand and interact with people of different cultural backgrounds is assuming greater relevance (Chalkiadaki, 2018). Education abroad has become a common means to enhance students' intercultural skills and develop global mind-sets. Over the past two decades, education abroad participation multiplied by $263 \%$ in the United States increasing from 129,770 students in 1998 to 341,751 by 2018 (IIE, 1999; IIE, 2019). American institutions reported another 38,401 students enrolled in noncredit work, internships, volunteerism or research abroad in the 2017/2018 academic

(C) Jennifer Fong. Published in Higher Education Evaluation and Development. Published by Emerald Publishing Limited. This article is published under the Creative Commons Attribution (CC BY 4.0) license. Anyone may reproduce, distribute, translate and create derivative works of this article (for both commercial and non-commercial purposes), subject to full attribution to the original publication and authors. The full terms of this license may be seen at http://creativecommons.org/licences/by/4.0/ legalcode

This work was supported by The National Science Foundation [grant \#1545917]

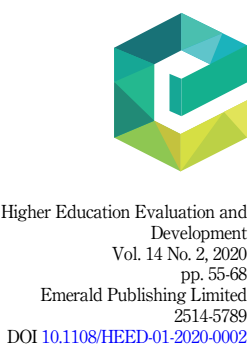


HEED

14,2

year. In addition, short-term programs, generally defined as less than eight weeks, account for the largest growth in education abroad (IIE, 2019). Over 65\% of students will opt for shortterm international experiences due to financial, language, academic or personal reasons (Gaia, 2015; IIE, 2019). This trend is likely to continue as educational stakeholders deem international experiences an important aspect of developing global competencies during the college experience.

Despite the continued growth of education abroad, particularly short-term and nonstudy abroad programs, their effectiveness to promote intercultural learning objectives lacks concrete evidence. Prior research demonstrates participants improved intercultural skills such as global awareness, openness to cultural differences and communicating with people of different backgrounds (Clarke et al., 2009; Kitsantas and Meyers, 2002; Williams, 2005). Yet, recent studies demonstrate that shorter programs may in fact limit students' development or even reinforce cultural stereotypes due to multiple factors related to: limited opportunities to engage those in the host culture (Bunch et al., 2018; Medina-Lopez-Portillo, 2004), lack of proactive interventions to promote intercultural learning, such as cultural mentors (Vande Berg, 2009), or inadequate program designs (Jackson, 2008).

Sending students to another country may not yield successful learning, even though participation in education abroad is presumed to maximize intercultural interactions. As Vande Berg (2009) asserts, students may regress or make few gains in intercultural learning when "left to their own devices" (p. 14). In other words, exposure and contact within different cultures do not on their own increase tolerance for cultural others or foster intercultural development; it must be actively worked toward (Amir, 1969; Vande Berg, 2009). Intentional programming that supports participants throughout the international experience is suggested to cultivate learning (Jackson, 2008).

Furthermore, growth in education abroad warrants institutions provide evidence of its value as the trend of outcome assessments in higher education continues. Increasingly stakeholders "want assurances that institutions will provide the knowledge, skills and awareness that will contribute directly to success after graduation" (Vande Berg, 2001, p. 31). Education abroad programs are no exception. By assessing what students learn from their international experiences, institutions can focus on ensuring that student learning remains at the forefront of such activities, instead of benchmarks such as enrollment numbers. In this sense, they can redirect resources more efficiently and maximize the program's impact (Siaya and Hayward, 2003). This necessitates institutions identify the skills and knowledge students acquire from experiences abroad and how they can be applied in their academic and professional careers (Williams, 2005).

To date, most research conducted on education abroad focuses on semester or year-long programs. Short-term and nonstudy abroad programs that do not easily fit into these traditional models have only recently been tracked and documented. For example, The US Doors Report is published by the Institute of International Education (IIE), the largest source of data on international exchanges for American students. The organization first collected data for "non-credit educational experiences including volunteering and service learning" beginning in 2012-2013 and published its findings in 2014 (IIE, 2014). Consequently, there is a dearth of data and research on nonstudy or short-term education abroad programs and their overall effectiveness and impact on students' intercultural learning.

This study examines the US-Taiwan Partnerships for International Research and Education (PIRE) program, a five-year interdisciplinary project headquartered at a large research university in the Northeast United States. This program, which began in 2015, receives financial support from the National Science Foundation (NSF) and the Ministry of Science and Technology in Taiwan (Ministry of Science and Technology, 2019). Each summer fewer than ten US juniors and seniors from a university in the Northeast United States and another participating East Coast university are recruited to conduct research in the fields of 
atmospheric science, meteorology and social science in Taiwan. Women and students from underrepresented groups in STEM are particularly encouraged to apply. Before beginning their research, the students complete a five-week culture course held at the university introducing students to Taiwanese culture and the Mandarin language. The students spend the following seven weeks in Taiwan conducting research at participating governmental organizations under the guidance of program professors and graduate students. Each student is assigned to a coexisting research project. Students also partake in various cultural activities and presentations hosted by the two partner universities in Taiwan. Activities held at the university are intended to facilitate relationships between students and encourage intercultural interactions. During weekends, students can explore local surroundings with their classmates. In culmination of the program, the PIRE undergraduates are responsible for a final report and presentation and receive feedback from their research advisors and peers.

According to the NSF, the purpose for international research experiences, such as USTaiwan PIRE, is to support undergraduates and graduates in "high-quality international research, education and professional development experiences" (NSF, 2017). The aim is to equip students with the necessary skills to succeed in a global society through experiences that "enhance transferable skills and expand professional networks" (NSF, 2017, 2018). The primary objectives for the US-Taiwan PIRE are: (1) to train students with the necessary knowledge and skills to be effective in addressing global climate issues, (2) to institutionalize PIRE's academic programs, (3) to foster a culture of interdisciplinary research to better understand extreme weather and solutions and (4) to build cross-cultural awareness among participants through education abroad programming.

This research project focuses on the last objective related to the intercultural learning of the 2018 US cohort of undergraduates, examining the program's impact on participants as measured by the cross-cultural adaptability inventory (CCAI). For this study, intercultural learning refers to the process of becoming more aware of and understanding one's own culture and others. Cross-cultural adaptability is expressed as the ability to effectively interact with people of different cultural backgrounds and to adjust living in another culture (Kelley and Meyers, 1995a). The study was guided by the following research questions:

$R Q 1$. How do the cross-cultural adaptability skills of undergraduates change over the course of a summer internship experience abroad?

$R Q 2$. To what extent does the intercultural learning evident from the quantitative results differ from the qualitative findings?

\section{Conceptual framework, short-term education abroad and cross-cultural adaptability inventory}

2.1 Conceptual framework

Cross-cultural adaptability in education abroad literature is interchangeably referred to as intercultural competence, cross-cultural adaptation, global awareness or intercultural effectiveness. The primary goal is to function effectively in various cultural contexts based on one's knowledge, skills and attitudes (Deardorff, 2006). A few primary skills that comprise cross-cultural adaptability include emotional resilience or the ability to deal with the psychological challenges of living in a foreign setting (Hammer et al., 1978; Ting-Toomey, 1999). Individuals may experience varying levels of mental and emotional confusion as a result of the new environment, particularly for first-time travelers. Learning to cope and adapt to stresses, however, can yield new cultural behaviors and understanding and contribute toward increased effectiveness in unfamiliar settings (Kim, 2001).

Flexibility and open-mindedness are also noted as key attributes to cross-cultural adaptability. Staying open to cultural differences has been referred to as tolerance of
Evaluation of an education abroad program 
HEED 14,2

ambiguity (Ting-Toomey, 1999). Deardorff (2006) includes cognitive flexibility and discernment as essential for adapting to new environments. Additionally, cultural empathy and perceptual sensitivity are skills individuals can apply when their mental and behavioral habits are ineffective in new cultural settings. These are expressed as being attentive to verbal and nonverbal cues and communication dynamics in interpersonal relations (Kelley and Meyers, 1995a). Unfamiliar situations may cause an individual to question their personal values and perspectives, creating additional internal stress (Kim, 2001). An individual who can remain steady in their beliefs and identity, while also respecting those in the target culture, possesses personal autonomy and self-confidence. Kelley and Meyers (1995b) posit these are important skills for a more successful adjustment in different cultural contexts.

\subsection{Short-term education abroad programs}

Though most of the education abroad literature examines semester and year-long programming, there are a greater number of studies exploring the impact of shorter programs and intercultural exchanges such as internships abroad that offer unique experiences beyond those provided through study abroad (Fantini and Tirmizi, 2006). The literature illustrates participant improvements in the following areas: (1) acceptance and appreciation of cultural differences, (2) cross-cultural skills and knowledge, (3) career development and (4) personal growth and development (Adler et al., 2005; Anderson et al., 2006; Black and Duhon, 2006; Chieffo and Griffiths, 2004; Czerwionka et al., 2015; Demetry and Vaz, 2017; Gaia, 2015).

In Demetry and Vaz's (2017) study, interns engaged in $30 \mathrm{~h}$ of intercultural learning curriculum during an eight-week research abroad program. Using a mixed-methods design, the researchers found that students who worked in cross-national teams exhibited the most intercultural awareness and sensitivity versus students working in US-only teams. Despite the fact that overall growth for the group was not demonstrated from the quantitative findings, interview responses indicated some intercultural learning among both groups. The differences in findings highlight the challenges of measuring development. Thus, the authors suggest a mixed-methods approach in assessing how intercultural exchanges affect learning.

Matherly et al. (2015) administered a pre- and postprogram survey assessing undergraduates' intercultural learning during a summer research internship abroad. Student interns demonstrated higher levels of cross-cultural skills, such as effective communication and collaboration in the host culture, and technical research skills, in comparison to the on-campus research group. They also showed increased knowledge and self-efficacy conducting academic research and living in another country. Students perceived the program to effectively prepare them for collaboration in cross-cultural settings. Other research on international internships asserts that students have greater chances to apply what they have learned in the classroom, gain hands-on work experience and develop important skill sets that may improve employability (Adler et al., 2005).

These findings align with previous research that indicates that short-term programs of at least six weeks can have a significant impact on students academically, professionally and personally, given sufficient resources and planning are involved (Dwyer, 2004; Vande Berg, 2009). Such program designs may include predeparture curriculum, regular opportunities for mentoring, weekly written reflections and re-entry programs that help students make sense of their experiences (Demetry and Vaz, 2017; Matherly et al., 2015).

\subsection{Cross-cultural adaptability inventory (CCAI)}

The CCAI was determined as the instrument most fit for assessing the intercultural learning of the PIRE undergraduates during their summer in Taiwan. Specifically, the inventory assesses an individual's effectiveness in culturally diverse settings based on four dimensions: 
(1) emotional resilience, (2) flexibility/openness, (3) perceptual acuity and (4) personal autonomy.

Based on the CCAI handbook, Table 1 details the four cross-cultural dimensions. Emotional resilience is expressed as an individual's ability to handle challenges, cope with unfamiliar experiences and maintain a positive attitude. Flexibility and openness reflect tolerance of differences, while enjoying the company of diverse people and experiences. The dimension of perceptual acuity involves being attentive to verbal and nonverbal cues and accurately communicating with individuals in the host culture. Lastly, personal autonomy includes having a strong value system, respect and responsibility for self and others (Kelley and Meyer, 1995b). Together the four adaptability traits comprise one's willingness and ability to understand and work effectively in different cultures (Kitsantas, 2004).

\section{Methodology}

\subsection{Participants}

A total of six US undergraduates were selected by PIRE professors to participate in the summer internship program. Five students studied at the primary university and one at the partner institution. Four students majored in Atmospheric Sciences and Meteorology, while two students were majoring in a Social Science field. Table 2 shows the demographics of the participants including: gender, age, class level and previous travel outside of North America.
Emotional resilience Flexibility/ openness Perceptual acuity

Personal autonomy

Note(s): From The MN: NCS Pearson
Evaluation of an education abroad program

\author{
Assesses the ability to rebound from challenges, cope the unfamiliar and maintain a \\ positive attitude \\ Assesses the ability to be tolerant of differences, nonjudgmental, and be open to various \\ ways of thinking and behaving \\ Assesses the ability to be empathetic and attentive to verbal and nonverbal behaviors \\ and communication dynamics \\ Assesses the ability to be self-directed, have a personal system of values and beliefs and \\ to respect oneself and others
}

Table 1.

Four dimensions of the CCAI

\begin{tabular}{lrr}
\hline Characteristic & $n$ & \\
\cline { 1 - 2 } Gender & & \\
Male & 2 & \\
Female & 4 & \\
Age & 1 & \\
$\leq 20$ & 4 & \\
$21-24$ & 1 & \\
$\geq 25$ & & \\
Class level & 0 & \\
Freshman & 1 & \\
Sophomore & 2 & Table 2. \\
Junior & 3 & Characteristics \\
Senior & & of study \\
Previous travel experience outside of North America & 3 & participants $(n=6)$ \\
Yes & 3 & \\
No & &
\end{tabular}


HEED

14,2

60

All six of the students agreed to participate in this research study with the understanding that the purpose was to explore how the program impacted their intercultural awareness and learning. Due to the circumstances of students, four of the six undergraduates completed both the pre- and postsurveys, while five students were available for the postprogram interview. Each student signed consent forms before the start of the program. Students could opt out of participating in the study at any time without any consequence to academic standing or program status.

\subsection{CCAI survey}

To assess the development of cross-cultural skills over the course of the program, a pre- and postprogram CCAI was distributed to students. This self-reported instrument is designed to measure an individual's abilities to adapt to different cultural contexts and identify areas for improvement (Kelley and Meyers, 1995a). The survey was administered online to students one week before departure and one week after the students returned to the United States to measure any changes in intercultural learning.

\subsection{Observations and interviews}

Participant observations and semistructured interviews were conducted in addition to the administration of the CCAI survey to better understand the students' experience from multiple perspectives and their individual responses. The researcher recorded field observations of students for two weeks at their respective internship sites and during the organized cultural activities. Insights from informal conversations with students enriched the interview responses and qualitative data. In addition, field notes from observations provided information about the quantity and quality of interactions between students and locals.

Interviews were conducted via video through an online platform two weeks upon the students' return to the United States. Five of the six students were available for the interviews, lasting on average 20 min per student. Each interview had five semistructured questions designed to elicit information about the students' experiences in Taiwan in relation to the four dimensions of cross-cultural adaptability.

\subsection{Data analysis methods}

Case study methods allow the researcher to collect and examine multiple data sources simultaneously throughout the study (Hancock and Algozzine, 2006). For this reason, analysis of the quantitative and qualitative data commenced as soon as data collection began. The demographic questionnaires and pre- and postsurveys were summarized in tabular form. Survey findings were exported to a spreadsheet to compare individual and group outcomes using the four CCAI scale dimensions of: (1) emotional resilience, (2) flexibility/ openness, (3) perceptual acuity and (4) personal autonomy.

The qualitative data were categorized into the four cross-cultural dimensions, which provided the theoretical framework. Transcriptions and written notes from interviews and observations were organized using NVivo qualitative software. Analysis of the data included rereading field notes and transcripts to identify particular themes related to cross-cultural skills and intercultural learning. However, the semistructured interviews also allowed for open-ended questions and additional responses that were included in the review. Interjections and filled pauses from the interviews, including "um" and "hmm," were removed from the final transcripts to ease the reading of findings. The purpose of the mixed-methods data analysis was to assess if any changes in cross-cultural adaptability skills occurred prior to and after the program and to what extent quantitative results varied from qualitative results. All forms of data from the surveys, observations and interviews were collected confidentially and kept in a secure environment. Participants and universities were assigned pseudonyms throughout the study. 


\section{Primary findings}

4.1 Changes in students' intercultural awareness and cross-cultural skills

The findings suggest that intercultural development occurred in specific areas of crosscultural adaptability. Specifically, the quantitative findings for the cohort showed growth in two of the four CCAI scales: flexibility/openness and perceptual acuity. In other words, students perceived themselves to be more flexible and open to new experiences and had an increased awareness of cultural differences. However, the CCAI results reflected minimal to no growth for the areas of emotional resilience and personal autonomy.

Table 3 details the predeparture and postprogram CCAI scores for the group as a whole and the percentage of change. Interestingly, qualitative findings seemed to reflect higher levels of development in each dimension, particularly in the areas of emotional resilience and personal autonomy. Field observations and interview responses demonstrated that students learned to navigate challenges living in a foreign environment and developed a greater sense of self-confidence and independence as a result of the internship experience.

\subsection{Students' perspectives about their experiences and intercultural learning}

4.2.1 Emotional resilience. Students predominantly coped with difficulties and the ambiguities of living abroad by confiding in their US classmates and relying on themselves more. Although a couple students showed decreases in emotional resilience in the pre- and postsurvey scores (Table 4), their interview responses reflected an increase in learning to cope with challenges. In particular, students found communicating with classmates as an effective way to ease some of the difficult feelings experienced during their time abroad.

\begin{tabular}{lccc}
\hline CCAI category & Predeparture score & Postprogram score & Change $(\Delta)$ from start to end of program \\
\hline Emotional resilience & $350 / 432$ & $348 / 432$ & $-0.5 \%$ \\
Flexibility/openness & $285 / 360$ & $303 / 360$ & $+5.0 \%$ \\
Perceptual acuity & $209 / 260$ & $215 / 260$ & $+2.5 \%$ \\
Personal autonomy & $136 / 168$ & $136 / 168$ & $0.0 \%$
\end{tabular}

Evaluation of an education abroad program

\begin{tabular}{|c|c|c|c|c|c|}
\hline & Student & Pre & Post & Change & \\
\hline \multirow[t]{4}{*}{ Emotional resilience scale (self-confidence) } & A & 104 & 104 & 0 & \\
\hline & $\mathrm{B}$ & 71 & 74 & +3 & \\
\hline & $\mathrm{C}$ & 92 & 91 & -1 & \\
\hline & $\mathrm{D}$ & 83 & 79 & -4 & \\
\hline \multirow[t]{4}{*}{ Flexibility/openness scale (tolerance) } & $\mathrm{A}$ & 80 & 85 & +5 & \\
\hline & $\mathrm{B}$ & 73 & 82 & +9 & \\
\hline & $\mathrm{C}$ & 73 & 75 & +2 & \\
\hline & $\mathrm{D}$ & 59 & 61 & +2 & \\
\hline \multirow[t]{4}{*}{ Perceptual acuity scale (empathy) } & A & 56 & 60 & +4 & \\
\hline & $\mathrm{B}$ & 52 & 55 & +3 & \\
\hline & $\mathrm{C}$ & 51 & 53 & +2 & \\
\hline & $\mathrm{D}$ & 50 & 47 & -3 & \\
\hline \multirow[t]{4}{*}{ Personal autonomy scale (independence) } & A & 36 & 36 & 0 & Table 4. \\
\hline & $\mathrm{B}$ & 32 & 33 & +1 & Individual participant \\
\hline & $\mathrm{C}$ & 34 & 34 & 0 & statistics by CCAI \\
\hline & $\mathrm{D}$ & 34 & 33 & -1 & dimension $(n=4)$ \\
\hline
\end{tabular}

Table 3. Summary of group statistics of pre- and post-CCAI $(n=4)$ 
HEED

14,2

Definitely talking with my [American] classmates helped because they had very similar issues with adjusting. We bonded over our challenges and it helped us to feel more confident overcoming them (Interviewee student D).

We would get dinner and talk it out. That's how we coped. I made pretty good friends with them because we confided in each other when we had our challenges or complaints. I'm not sure what I would've done if they were not there (Interviewee student E).

Some students demonstrated being able to deal with challenges in the lab setting and became more comfortable relying on themselves, instead of constantly seeking assistance from others.

It's definitely made me stronger because I learned not to go to my mentor right off the bat. I was able to work through the problem myself and ask for outside help less. Especially since our professors were busy a lot of the time ... I tried to look questions up on the Internet or turn to other resources instead of them having to sit down and explain everything to me. Doing it myself I actually absorbed the material better (Interviewee student C).

Handling the psychological challenges of a new environment was displayed more in some students than others. For instance, student B, who was a senior and had prior traveling experience, showed the highest gains in three of the four CCAI dimensions and the most improvement in emotional resilience. His response demonstrated awareness of obstacles such as language differences, but believed in his ability to adapt living in a new setting.

I did not find it too stressful. Of course, there were certain problems like ordering food and going into stores, but I managed. I would say the beginning was difficult just because you do not have the creature comforts from home ... maybe a bit of culture shock? But hanging around fellow students helped and getting to know people I worked with in the program helped make me feel more at home. I guess it's similar to any situation living abroad and like feeling a bit isolated and uneasy in the beginning, but then as time goes on you just start to feel more comfortable in your surroundings (Interviewee student B).

Ting-Toomey (1999) posits emotional resilience is necessary to navigate foreign settings as the experience can be accompanied by new levels of mental and emotional stresses. In particular, first-time travelers may experience even more difficulty in adjusting to their surroundings abroad. However, the challenges can also be an opportunity for the sojourner to encounter and handle challenges, learning how to more effectively adapt one's behaviors in unfamiliar cultural contexts (Kim, 2001).

4.2.2 Flexibility/openness. Flexibility is a dimension of cross-cultural adaptability characterized by individuals who remain open to different ways of thinking and behaving in their cross-cultural experiences (Kelley and Meyers, 1995b). The students who were more open and culturally tolerant in Taiwan seemed to have a positive influence on their classmates' curiosity about new foods or experiences.

I was really open to trying new foods before, but I feel just as if, if not more open from this experience. I thought maybe I should try things before judging them as good or bad. I noticed some of my classmates would only try something after I did, which is nice I could help them feel like it wasn't such a terrible thing. Plus it was more fun since it didn't feel like anyone was being left out (Interviewee student C).

From the observations, these students encouraged other classmates to try things even though they were initially hesitant. Student B, for instance, much less willing to try new foods was encouraged by student A to participate in a cultural eating contest. Despite being tentative at first, student B participated in the game with his US and Taiwanese classmates, allowing him an opportunity to try new foods he would not have otherwise.

I tried to make an effort to try their local foods and not eat at fast food restaurants or Western-style restaurants ... I remember my classmate asked me to participate in an eating contest and I knew I 
was going to have to try something I probably didn't want to. But it really helped me to get out of my comfort zone, to be honest. I never would've tried pig's blood on my own, that's for sure! (Interviewee student B)

\subsubsection{Perceptual acuity}

When asked about how students interpreted others' feelings and behaviors in Taiwan, this topic yielded limited responses. Perceptual acuity or the ability to perceive others' feelings and verbal and nonverbal behaviors in a nonjudgmental way is at the foundation of building cultural empathy. Students exhibited limited understanding or willingness to value the cultural differences they observed in the host culture. They expressed challenges mostly in communicating with their fellow peers or mentors.

I didn't really go out as much as I probably should have because I was scared to say the wrong thing when ordering food or buying things. I honestly felt like if I got lost I wouldn't be able to communicate with the locals and find my way back to the dorms, so I kind of just stayed in a lot (Interviewee student E).

I was trying to learn the language throughout, but even still 2 months of trying to learn Mandarin with an app and talk to locals is not enough to be useful ... When it came to being in the labs, these people tried, but some didn't have the courage to use their English or they couldn't. So we just didn't talk that much (Interviewee student A).

Despite student A showing the most growth in this area compared to his classmates, the interview responses highlight nuances in perspectives the surveys do not capture. His use of the words "these people" indicates a sort of distance between himself and those who are culturally different than him or who might not speak the same first language. Yet, the student's survey indicates a four-point increase from postprogram scores, the highest gains in the group.

In addition, when asked to describe some observations of the differences they experienced in the host culture, most of the students had difficulty recalling specific instances and mentioned surface-level cultural differences related to daily life.

I learned a lot of new things. I was more open to the differences. The people were super nice ... the speed in Taipei is still fast paced (Interviewee student D).

I have no problem with the culture. It's feels similar. People are similar around the world, so it was nothing shocking (Interviewee student A).

Culturally I didn't think there were big issues. They seem to be very receptive towards Americans and friendly. That made things easier (Interviewee student B).

These findings are consistent with prior research on short-term programs that show students may not have ample opportunities for meaningful exchange and reflection while in the host culture. Although students can display some adaptive changes, such as conforming to the social etiquette, deeper-level internal transformation can take much longer (Kim, 2001). In addition, other studies examining intercultural learning and study abroad show students may actually regress in their development, regardless of program duration, from a lack of interventions to support participants' learning (Vande Berg, 2009). This underscores the importance of program design, in which learning about and understanding cultures beyond superficial levels are optimized (Dwyer, 2004; Medina-Lopez-Portillo, 2004).

On the other hand, some students exhibited higher levels of cultural empathy in their intercultural interactions. Student B, who had the second highest score in perceptual acuity, showed awareness in the role he played while communicating with individuals in Taiwan. He willingly talked to and interacted more frequently with his lab mates and locals, despite knowing little Mandarin.
Evaluation of an education abroad program 
HEED

14,2

I tried my best to make conversation with my lab mates and the local people, even though I knew there was going to be some miscommunication. I think you have to try and put yourself out there sometimes because it can be scary speaking a new language as I've learned with Mandarin (Interviewee student B).

Student B's response displays a sense of empathy for the locals, as he relates through the shared experience of struggling to learn another language. This ability to be attentive toward other's feelings and behaviors is a key component in understanding individuals who are different from oneself (Kelley and Meyers, 1995a). As a result, the student reported more meaningful intercultural contact while in the host culture compared to his classmates.

4.3.1 Personal autonomy. The ability to remain steady in one's beliefs and identity, while also respecting others, is a skill that is important for a more successful adjustment in different cultural contexts. Similar studies on intercultural learning and education abroad have shown increases in participants' levels of confidence (Maharaja, 2018). Contrary to the survey group results, which showed no overall changes from pre- and postscores in the personal autonomy scale, interview responses revealed positive changes in students' levels of confidence and selfefficacy. Students $C$ and D displayed an increased ability to reason and make decisions on their own, taking greater responsibility when faced with an issue.

I was able to do things on my own the more I worked with the data, so I didn't have to rely so much on one student in the lab. I just started to ask myself questions before automatically asking for hel . . . If anything this program has helped me to think for myself more and gave me confidence to do research in another country" (Interviewee student C).

The students admitted feeling more comfortable since Student D, who spoke Mandarin, helped them navigate their way around. From my observations, student D willingly took on a leadership role, acting as a translator and guide for her classmates. At the internship site, she was able to consider different perspectives of her peers and at times debate with her managers about certain ideas and topics. She expressed taking greater responsibility for herself by speaking up and asking questions more often, something she said she rarely did in school.

Student A, who had prior international experiences in non-Asian countries, reported the highest prescores in the cohort for each of the four dimensions. His ability to make choices independently, traveling and navigating daily life on his own was reflected in the following excerpt.

I found Taipei to be very similar to NYC, in that the basic systems are the same, like public transportation. I was also trying to learn the language throughout my time there ... I would try to order food in Mandarin and speak to locals when I had the chance. Overall, I didn't have much problem getting around after a few days. I went to explore even if the other students didn't want to join because I wanted to immerse myself as much as possible in the culture, and I'm glad I did (Interviewee student A).

Along with increasing self-efficacy, students' willingness to live in other cultures and professional plans and future goals were impacted. This supports research that shows international programs such as service-learning opportunities have significant influence on students' decisions about future goals and career aspirations upon their return to the United States (Wanasek, 2005).

I have much more confidence in myself to succeed in this major and further motivation to be a physical scientist. It's bolstered my interest to explore other parts of the world and maybe not live in the US my whole life. I drew a lot of inspiration from this experience (Interviewee student A).

I definitely am thinking of a career or job abroad now. The experience in Taiwan and the connections I made with the professors helped me to see that it's possible and rewarding to work in another country" (Interviewee student D). 


\section{Discussion}

The aim of this case study was to understand the impact of an internship experience abroad on students' intercultural learning. Analyses of the findings suggest that participants improved in particular cross-cultural skills. Quantitative findings indicated no effect for two of the four CCAI dimensions; however, interview responses and observations suggest that some growth did occur in emotional resilience and personal autonomy. Although students experienced resistance, they became more comfortable with ambiguity, tried new foods and experiences they did not think they would before the trip and developed higher levels of selfconfidence and awareness. However, deeper-level internal transformation generally requires longer durations in the new culture (Kim, 2001). Despite interactions within the host culture, meaningful exchanges and reflection were limited. Students seemed less cognizant of cultural verbal and nonverbal behaviors and understanding of these differences.

Additionally, some students who showed positive overall growth from the surveys did not reflect a sense of adaptability as suggested from interview responses. One reason for this may be due to students' positive perception and high regard for their levels of intercultural sensitivity, rendering self-reported findings higher relative to the qualitative findings. Students may be less aware of what they do not know and thus assume themselves to be more competent than they actually are (Jackson, 2008).

Interestingly, students who displayed the highest levels of intercultural awareness and understanding of cultural differences from my observational and interview findings reported the lowest scores at the start of the program and had the most significant drops in scores by the end of the program. Related to Jackson's (2008) analysis of some students' inflated sense of intercultural competence, persons of different cultural backgrounds, such as from East Asian countries or less dominant cultures where self-regard is less valued, can tend to underestimate their own abilities (Heine et al., 1999). In contrast, the highest starting scores and overall gains were reported from students of Western background. The two participants with the highest gains from the questionnaire were also both males. Though limited research exists on gender as a predictor of cross-cultural development, a study by Medina-Lopez-Portillo (2004) found males from the study reported higher intercultural development scores overall compared to females.

The starting conditions of students may also play a role in development. The decline in scores for some participants may be attributable to the fact that they arrived in the host culture with relatively higher levels of cross-cultural abilities than their peers. As their awareness of cultural differences increased, they became more sensitive to the gaps in their own intercultural abilities and knowledge. Negative changes in scores may reflect a heightened sense of incompetence, but overlook the nuances involved in growth as the individual begins to encounter and process intercultural difficulties that less experienced students may not be aware of.

Additionally, students who had previous traveling experiences or who were older seemed better able to deal with the psychological stresses of living abroad. This supports research that shows individuals with prior experiences abroad have a positive impact on students' intercultural attitudes (Heinzmann et al., 2015). As unfamiliar situations such as those encountered in new environments can lead to additional internal stress, having and maintaining a sense of one's beliefs and identity is also seen as an important aspect in adapting to another culture (Kim, 2001). Students who had more knowledge and experience from prior intercultural exchanges seemed to exhibit more confidence and adjust to their environment quicker.

Based on the interview responses, all the participants perceived the program to increase their cultural awareness and build important skill sets. The experience encouraged two students to further pursue research or work abroad in the future. Research on international internships and service-learning opportunities indicate a positive long-term impact on 
HEED

14,2

participants' postgraduation plans and career goals (Dwyer and Peters, 2004; Wanasek, 2005). A re-entry program that includes active reflection and evaluation may better assist participants in translating what they learned in preparation for future careers (Matherly et al., 2015). This underscores the importance of purposeful program design, which may scaffold intercultural learning, in order for students to make sense of and enhance their international experiences (Matherly et al., 2015; Medina-Lopez-Portillo, 2004).

\section{Conclusion and limitations}

The study found the internship program abroad to have a positive impact on students' development of intercultural skills related to academic, personal and professional growth. Participants reported an increased awareness of cultural differences, willingness to communicate with individuals despite language barriers and confidence navigating a foreign environment. However, students expressed more superficial observations of differences and displayed less awareness of the role they played in their intercultural exchanges. This could be due to inadequate time in the host culture, limited interactions or lack of cultural knowledge and preparation. Further research on the impact of program interventions, such as cultural mentoring, predeparture classes or active reflection and discussions of students' intercultural experiences, may assist in optimizing learning, particularly for programs of shorter durations.

This case study involved a small purposive sample of students from a specific program. Therefore, the results are not generalizable to other programs with different student populations. The research utilized a pre- and postprogram assessment measure and postprogram interview. A preinterview could have provided additional descriptive data as to changes in students' perspectives as a result of participation in the program. Lastly, following up with students one semester or more after program completion would provide insight as to the long-term impact of the program and how students utilized their skills and knowledge going forward. Further research addressing such limitations could inform future studies on the impacts of education abroad on intercultural learning.

\section{References}

Adler, R.K., Loughrin-Sacco, S.J. and Moffatt, R. (2005), "The role of experiential learning in preparing global-ready graduates", in Tillman, M. (Ed.), Impact of Education Abroad on Career Development, American Institute For Foreign Study, Stamford, CT, pp. 15-17.

Amir, Y. (1969), "Contact hypothesis in ethnic relations", in Weiner, E. (Ed.), The Handbook of Interethnic Coexistence, Continuum Publishing (1998), New York, NY.

Anderson, P.H., Lawton, L., Rexeisen, R.J. and Hubbard, A.C. (2006), "Short-term study abroad and intercultural sensitivity: a pilot study", International Journal of Intercultural Relations, Vol. 30, pp. 457-469.

Black, H.T. and Duhon, D.L. (2006), "Assessing the impact of business study abroad programs on cultural awareness and personal development", Journal of Education for Business Jan/Feb, pp. 140-144, 2006.

Bunch, J.C., Rampold, S.D., Cater, M. and Blackburn, J.J. (2018), "The impact of a short-term international experience on undergraduate students' cultural competency", Journal of Agricultural Education, Vol. 59 No. 4, pp. 120-136.

Chalkiadaki, A. (2018), "A systematic literature review of 21st century skills and competencies in primary education”, International Journal of Instruction, Vol. 11 No. 3, pp. 1-16.

Chieffo, L. and Griffiths, L. (2004), "Large-scale Assessment of student attitudes after a short-term study abroad program”, Interdisciplinary Journal of Study Abroad, Vol. 10, pp. 165-177.

Clarke, I., Flaherty, T., Wright, N.D. and McMillan, R.M. (2009), "Student intercultural proficiency from study abroad programs", Journal of Marketing Education, Vol. 31 No. 2, pp. 173-181. 
Czerwionka, Artamonova and Barbosa (2015), "Intercultural knowledge development: evidence from student interviews during short-term study abroad", International Journal of Intercultural Relations, Vol. 49, pp. 80-99.

Deardorff, D.K. (2006), "Identification and assessment of intercultural competence as a student outcome of internationalization”, Journal of Studies in International Education, Vol. 10 No. 3, pp. 241-266.

Demetry, C. and Vaz, R.F. (2017), "Influence of an education abroad program on the intercultural sensitivity of STEM undergraduates: a mixed methods study", Advances in Engineering Education, Vol. 6 No. 1, pp. 1-32.

Dwyer, M.M. (2004), "More is better: the impact of study abroad program duration", Interdisciplinary Journal of Study Abroad, Vol. 10, pp. 151-163.

Dwyer, M.M. and Peters, C.K. (2004), The Benefits of Study Abroad, IES Abroad, available at: http:// www.iesabroad.org.

Fantini, A. and Tirmizi, A. (2006), Exploring and Assessing Intercultural Competence, World Learning Publications, available at: http://digitalcollections.sit.edu.

Gaia, A.C. (2015), "Short-term faculty-led study abroad programs enhance cultural exchange and selfawareness", The International Education Journal: Comparative Perspectives, Vol. 14 No. 1, pp. 21-31.

Hammer, M.R., Gudykunst, W.R. and Wiseman, R.L. (1978), "Dimensions of intercultural effectiveness: an exploratory study", International Journal of Intercultural Relations, Vol. 2, pp. 382-393.

Hancock, D.R. and Algonzzine, B. (2006), Doing Case Study Research: A Practical Guide for Beginning Researchers, Teachers College Press, New York, NY.

Heine, S.J., Lehman, D.R., Markus, H.R. and Kitayama, S. (1999), "Is there a universal need for positive self-regard?”, Psychological Review, Vol. 106, pp. 766-794.

Heinzmann, S., Künzle, R., Schallhart, N. and Müller, M. (2015), "The effect of study abroad on intercultural competence: results from a longitudinal quasi-experimental study", The Interdisciplinary Journal of Study Abroad, Vol. 26, pp. 187-208.

Institute of International Education (IIE) (1999), Report on International Educational Exchange, Institute of International Education, available at: http://www.opendoors.iienetwork.org.

Institute of International Education (IIE) (2014), Open Doors: Non-credit Work, Internships, and Volunteering Abroad, 2011/12-2012/13, Institute of International Education, available at: $\mathrm{http} / / / \mathrm{www}$. opendoors.iienetwork.org.

Institute of International Education (IIE) (2019), Open Doors: Report on International Educational Exchange, Institute of International Education, available at: http://www.opendoors.iie network.org.

Jackson, J. (2008), "Globalization, internationalization, and short-term stays abroad", International Journal of Intercultural Relations, Vol. 32 No. 2008, pp. 349-358.

Kelley, C. and Meyers, J. (1995a), The Cross-Cultural Adaptability Inventory: Manual, NCS Pearson, Minneapolis, MN.

Kelley, C. and Meyers, J. (1995b), The Cross-Cultural Adaptability Inventory: Self-Assessment, NCS Pearson, Minneapolis, MN.

Kim, Y.Y. (2001), Becoming Intercultural: An Integrative Theory of Communication and Cross-Cultural Adaptation, SAGE Publications, Thousand Oaks, CA.

Kitsantas, A. (2004), "Studying abroad: the role of college students' goals on the development of cross-cultural skills and global understanding", College Student Journal, Vol. 38 No. 3, pp. 441-452.

Kitsantas, A. and Meyers, J. (2002), Studying Abroad: Does it Enhance College Student Cross-Cultural Awareness?, Education Resources Information Center, ED, pp. 456-648.
Evaluation of an education abroad program 
HEED 14,2

Maharaja, G. (2018), "The impact of study abroad on college students' intercultural competence and personal development. International research and review", Journal of Phi Beta Delta Honor Society for International Scholars, Vol. 7 No. 2, pp. 18-41.

Matherly, C., Phillips, S.R. and Chapman, C.A. (2015), "The impact of international research experiences on undergraduate learning", Paper Presented at the 122nd ASEE Annual Conference \& Exposition, Seattle, WA.

Medina-Lopez-Portillo, A. (2004), "Intercultural learning assessment: the link between program duration and the development of intercultural sensitivity", Interdisciplinary Journal of Study Abroad, Vol. 10, pp. 179-199.

Ministry of Science and Technology (2019), International Cooperation Programs, Taiwan Ministry of Science and Tech, available at: http://www.most.gov.tw.

National Science Foundation (NSF) (2017), International Research Experiences for Students (IRES), National Science Foundation, available at: http://www.nsf.gov.

National Science Foundation (NSF) (2018), Partnerships for International Research and Education (PIRE), National Science Foundation, available at: http://www.nsf.gov.

Siaya, L. and Hayward, F.M. (2003), Mapping Internationalization on US Campuses, American Council on Education, WA, DC.

Ting-Toomey, S. (1999), Communicating across Cultures, The Guilford Press, New York, NY.

Vande Berg, M. (2001), "The assessment of learning outcomes in study abroad", International Educator, Vol. 10 No. 2, p. 31.

Vande Berg, M. (2009), "Intervening in student learning abroad: a research-based inquiry", Intercultural Education, Vol. 20, pp. 15-27.

Wanasek, B. (2005), "International service-learning: impact on career choices”, in Tillman, M. (Ed.), Impact of Education Abroad on Career Development, American Institute For Foreign Study, Stamford, CT, Vol. 1, pp. 33-34.

Williams, T.R. (2005), "Exploring the impact of study abroad on students' intercultural communication skills: adaptability and sensitivity", Journal of Studies in International Education, Vol. 9 No. 4, pp. 356-371.

\section{Further reading}

Hammer, M.R., Bennett, M.J. and Wiseman, R. (2003), "Measuring intercultural sensitivity: the intercultural development inventory", International Journal of Intercultural Relations, Vol. 27, pp. 421-433.

Institute of International Education (IIE) (2016), Redefining International Education through Non-credit Education Abroad, Institute of International Education, available at: http://www.iie.org.

Martinez, A., Epstein, C. and Parsad, A. (2015), Evaluation of the National Science Foundation's Partnerships for International Research and Education (PIRE) Program, Abt Associates, available at: http://www.abtassociates.com.

\section{Corresponding author}

Jennifer Fong can be contacted at: jfong@albany.edu

For instructions on how to order reprints of this article, please visit our website:

www.emeraldgrouppublishing.com/licensing/reprints.htm

Or contact us for further details: permissions@emeraldinsight.com 